\title{
Aminomethanol water elimination: Theoretical examination
}

\author{
Michael T. Feldmann ${ }^{\text {a) }}$ \\ Center for Advanced Computing Research, MC 158-79, California Institute of Technology, Pasadena, \\ California 91125 \\ Susanna L. Widicus, Geoffrey A. Blake, ${ }^{\text {b) }}$ David R. Kent IV, ${ }^{\text {a) }}$ and William A. Goddard III ${ }^{\text {a) }}$ \\ Division of Chemistry and Chemical Engineering, MC 164-30, California Institute of Technology, \\ Pasadena, California 91125
}

(Received 26 January 2004; accepted 25 April 2005; published online 27 July 2005)

\begin{abstract}
The mechanism for the formation of hexamethylenetetraamine predicts the formation of aminomethanol from the addition of ammonia to formaldehyde. This molecule subsequently undergoes unimolecular decomposition to form methanimine and water. Aminomethanol is the predicted precursor to interstellar glycine, and is therefore of great interest for laboratory spectroscopic study, which would serve as the basis for observational searches. The height of the water loss barrier is therefore useful in the determination of an appropriate experimental approach for spectroscopic characterization of aminomethanol. We have determined the height of this barrier to be $55 \mathrm{kcal} / \mathrm{mol}$ at ambient temperatures. In addition, we have determined the infinite-pressure Rice-Ramsperger-Kassel-Marcus unimolecular decomposition rate to be $<10^{-25} \mathrm{~s}^{-1}$ at $300 \mathrm{~K}$, indicating gas-phase kinetic stability for typical laboratory and hot core temperatures. Therefore, spectroscopic characterization of and observational searches for this molecule should be straightforward provided an efficient formation mechanism can be found. (C) 2005 American Institute of Physics. [DOI: 10.1063/1.1935510]
\end{abstract}

\section{INTRODUCTION}

Presently there are over 100 known interstellar molecules, the great majority of which are organic. ${ }^{1}$ Theoretical models of grain surface chemistry predict precursors to the more complex compounds, such as simple alcohols and aminoalcohols. $^{2-4}$ Many potential grain surface reaction pathways are eliminated by the conditions imposed on these models, greatly simplifying the possible products of grain synthesis and eliminating the possibility for much larger organics to form on the grain surfaces. Gas-phase theoretical models of the chemistry in hot protostellar cores involving the products of grain surface reactions are therefore required to explain the formation of substantially larger organics under interstellar conditions. In these models, the temperature of the hot cores $(\sim 300 \mathrm{~K})$ near young stars leads to thermal evaporation of simple molecules, such as alcohols and aminoalcohols, from the grain surface. These molecules can then undergo gas-phase reactions to form more complex species such as amino acids, sugars, and other biologically important molecules.

The recent detection of glycolaldehyde $\left(\mathrm{CHOCH}_{2} \mathrm{OH}\right)$, simplest $\alpha$-hydroxy aldehyde, ${ }^{5}$ and dihydroxyacetone $\left[\mathrm{CO}\left(\mathrm{CH}_{2} \mathrm{OH}\right)_{2}\right]$ the simplest ketose monosaccharide ${ }^{6}$ in the hot core Sagitarrius B2(N-LMH) has confirmed the need for further experimental and observational investigations of these models. One proposed pathway involves both grain

\footnotetext{
a) Also at Material and Process Simulation Center, California Institute of Technology.

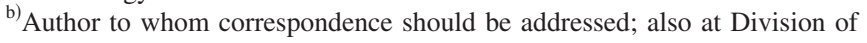
Geological and Planetary Sciences, California Institute of Technology. Electronic mail: gab@gps.caltech.edu
}

surface and hot core gas-phase chemistry for the formation of amino acids. In this pathway, the protonated forms of aminomethanol $\left(\mathrm{NH}_{2} \mathrm{CH}_{2} \mathrm{OH}\right)$ and aminoethanol $\left(\mathrm{NH}_{2} \mathrm{CH}_{2} \mathrm{CH}_{2} \mathrm{OH}\right)$ react with formic acid $(\mathrm{HCOOH})$ to yield the protonated forms of glycine and alanine, respectively. ${ }^{3}$ However, laboratory and observational data supporting the presence of these aminoalcohols remain incomplete. Therefore, the first step in the evaluation of this model is the complete spectroscopic characterization of aminomethanol and aminoethanol in order to search for them astronomically.

Aminoethanol is commercially available and the gasphase species is easily attainable. Its laboratory characterization has been completed, ${ }^{7,8}$ and observational searches are underway. In contrast, aminomethanol has not been isolated, and little is known about the stability of this molecule. It is proposed to form from the addition of ammonia to formaldehyde, and the energy barrier for this reaction is calculated (MP2/6-311++ $\mathrm{G}^{* *}$ ) to be $34.1 \mathrm{kcal} \mathrm{mol}^{-1}{ }^{9}$ In addition, the hexamethylenetetraamine formation mechanism proposes that aminomethanol (1) forms upon the addition of ammonia to formaldehyde in aqueous solution [Fig. 1 (Ref. 10)]. Aminomethanol then undergoes a water loss and converts to the highly reactive species methanimine (2). Further reactions lead to the formation of a stable intermediate cyclotrimethylenetriamine (3), with eventual conversion to the stable end product hexamethylenetetraamine (4).

The gas-phase reaction of formaldehyde and ammonia is the most promising route for laboratory production of aminomethanol. Reaction of this molecule with other species can be minimized by quenching the formaldehyde+ammonia reaction in a molecular beam. Characterization of aminometha- 


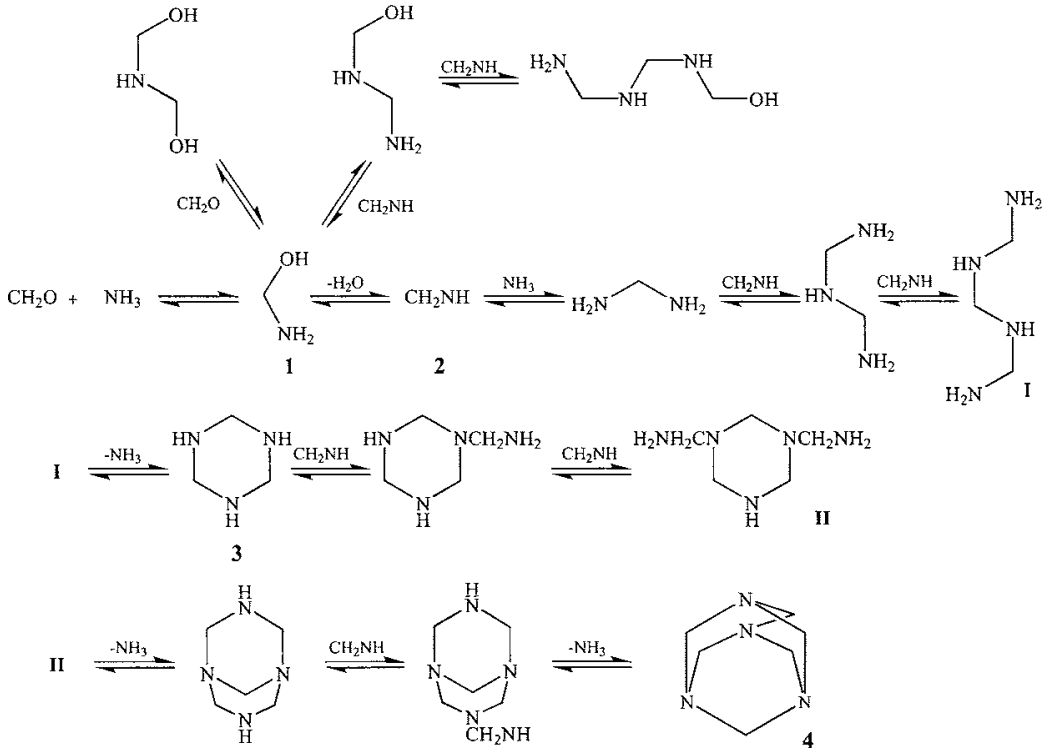

FIG. 1. Mechanism for reaction of formaldehyde and ammonia.

nol would therefore be possible if the barrier to the loss of water and conversion to methanimine is sufficiently high. The major route for destruction of aminomethanol in the interstellar medium is also through the water loss channel and conversion to methanimine. Therefore, determination of this barrier height will indicate the feasibility of laboratory production of aminomethanol as well as this molecule's potential stability in a hot core environment.

\section{THEORY}

The most simple methods one can employ for examining the quantum properties of small molecules are Hartree-Fock (HF) theory and density-functional theory (DFT: B3LYP, BLYP, and BP86). ${ }^{11-15}$ These are implemented using the JAGUAR (Ref. 16) package. Corrections to HF theory methods can take many forms, though this work focuses on $\mathrm{HF}^{17-20}$ MP2 $2{ }^{21-23} \mathrm{MP} 4,{ }^{21-23} \mathrm{CCSD},{ }^{21-24} \mathrm{CCSD}(\mathrm{T}),{ }^{21-24}$ and $\mathrm{QCI}(\mathrm{T})$ (Ref. 24) implemented in the MOLPRO package. ${ }^{25}$ Diffusion Monte Carlo ${ }^{26}$ (DMC) is also examined for selected species using the QMCBEAVER package. ${ }^{27-30}$

\section{CALCULATIONS}

\section{A. Methodology}

Full geometry optimization and transition state searches were completed using the B3LYP/cc-pVTZ (Ref. 31) level of theory with JAGUAR. These geometries were then fixed and single point energy calculations were completed using a variety of methods. Thermodynamic calculations were not completed at this level of theory because the cc-pVTZ basis set contains $f$-type functions, of which JAGUAR is unable to analytically take derivatives for thermodynamic calculations. Transition states were verified with analytic Hessian calculations. These geometries are shown in Fig. 2.

JAGUAR was used for full thermodynamic calculations using B3LYP/cc-pVTZ $(-f)$. This basis is the same as the full cc-pVTZ used to obtain the electronic energy but the $f$-type orbitals are removed. These calculations provided vibrational frequencies to calculate a zero-point energy correc- tion to the electronic energy as well as free-energy corrections.

A larger aug-cc-pVTZ (Ref. 25) basis set was used to determine the importance of diffuse functions in this mechanism. This larger basis set is ideal since it better describes the lower electron-density regions, particularly in the transition states. This basis set, however, was too large to run for all methods on our current computational resources. Where possible, the energies for this basis are given. The B3LYP/cc $-p \operatorname{VTZ}(-f)$ vibrational frequencies were used throughout to calculate thermodynamic corrections for all other method/ basis-set combinations.

\section{B. Calculational result}

Electronic energies were obtained with various methods using the cc-pVTZ basis. These results are found in Table I.

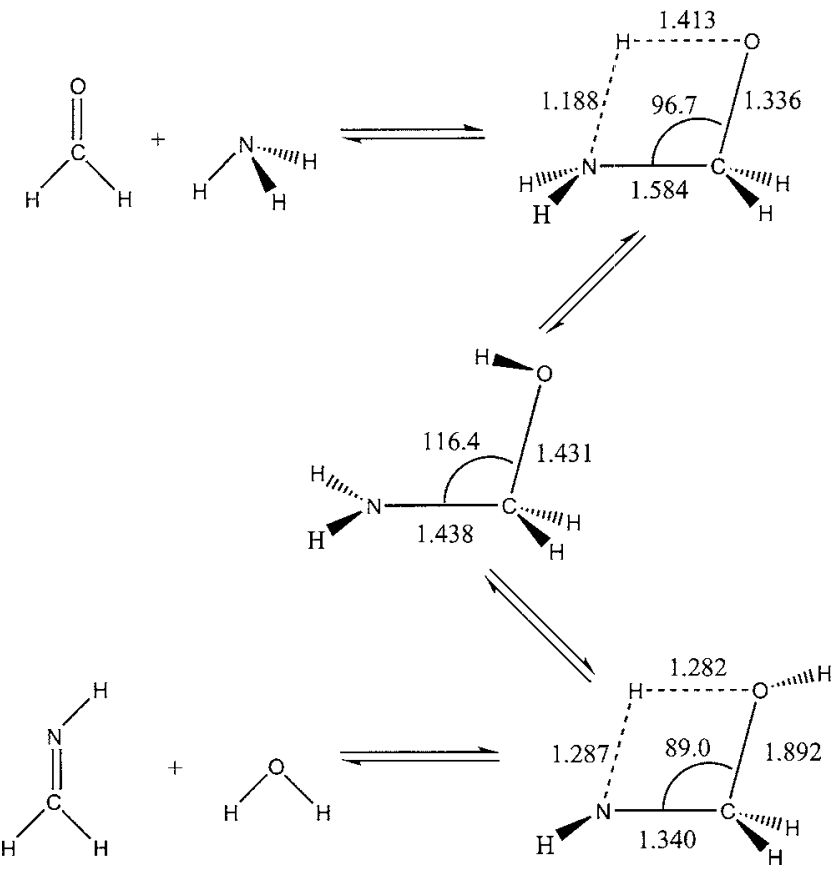

FIG. 2. Full mechanism of aminomethanol formation from $\mathrm{NH}_{3}$ and $\mathrm{CH}_{2} \mathrm{O}$ and decomposition to $\mathrm{CH}_{2} \mathrm{NH}$ and $\mathrm{H}_{2} \mathrm{O}$. 
TABLE I. Absolute energies (hartree) for various methods (basis: cc-pVTZ).

\begin{tabular}{|c|c|c|c|c|c|c|c|}
\hline Method & $\mathrm{NH}_{3}$ & $\mathrm{CH}_{2} \mathrm{O}$ & $T_{\mathrm{NH}_{3}+\mathrm{CH}_{2} \mathrm{O}}^{\dagger}$ & $\mathrm{CH}_{2}(\mathrm{OH}) \mathrm{NH}_{3}$ & $T_{\mathrm{H}_{2} \mathrm{O}+\mathrm{CH}_{2} \mathrm{NH}}^{\dot{\dagger}}$ & $\mathrm{H}_{2} \mathrm{O}$ & $\mathrm{CH}_{2} \mathrm{NH}$ \\
\hline B3LYPa & -114.5494 & -56.5847 & -171.0856 & -171.0634 & -171.0634 & -76.4599 & -94.6694 \\
\hline BLYP $^{a}$ & -114.5228 & -56.5569 & -171.0313 & -171.0936 & -171.0139 & -76.4413 & -94.6325 \\
\hline $\mathrm{BP}^{\mathrm{a}}{ }^{\mathrm{a}}$ & -114.5472 & -56.5827 & -171.0916 & -171.1513 & -171.0717 & -76.4596 & -94.6655 \\
\hline $\mathrm{HF}^{\mathrm{a}}$ & -113.9120 & -56.2178 & -170.0584 & -170.1464 & -170.0266 & -76.0569 & -94.0677 \\
\hline $\mathrm{HF}^{\mathrm{a}}$ & -113.9120 & -56.2177 & -170.0585 & -170.1464 & -170.0266 & -76.0568 & -94.0677 \\
\hline$M P 2^{b}$ & -114.3070 & -56.4529 & -170.7153 & -170.7841 & -170.6896 & -76.3186 & -94.4386 \\
\hline $\mathrm{MP}^{\mathrm{b}}$ & -114.3367 & -56.4734 & -170.7624 & -170.8314 & -170.7382 & -76.3330 & -94.4733 \\
\hline $\operatorname{CCSD}^{\mathrm{b}}$ & -114.3173 & -56.4655 & -170.7309 & -170.8052 & -170.7034 & -76.3245 & -94.4560 \\
\hline $\operatorname{CCSD}(\mathrm{T})^{\mathrm{b}}$ & -114.3337 & -56.4732 & -170.7584 & -170.8292 & -170.7336 & -76.3322 & -94.4725 \\
\hline $\mathrm{QCI}(\mathrm{T})^{\mathrm{b}}$ & -114.3343 & -56.4733 & -170.7593 & -170.8297 & -170.7347 & -76.3323 & -94.4729 \\
\hline $\mathrm{DMC}^{\mathrm{c}}$ & NA & NA & NA & $-170.965(7)$ & $-170.856(4)$ & $-76.393(3)$ & $-94.531(3)$ \\
\hline
\end{tabular}

JAGUAR.

${ }^{\mathrm{b}}$ MOLPRO.

${ }^{\mathrm{c}}$ QMCBEAVER.

To verify that the absence of diffuse functions was a valid assumption, several methods are compared in Table II with the aug-cc-pVTZ. ${ }^{16}$ These are corrected with the zero-point and thermochemical corrections at $300 \mathrm{~K}$ and 2.63 $\times 10^{-5}$ atm (typical laboratory conditions) in Tables III and IV. The free energies based on QCI(T)/cc-pVTZ base energies are given in Tables V and VI at total system pressures typical for laboratory and astrophysical conditions, respectively. These energies are given for various temperatures reflecting both laboratory and astronomic conditions, which allows for comparison of kinetics in these different environments. $^{32}$

\section{RESULTS AND CONCLUSIONS}

To the authors' knowledge this is the most complete theoretical study of aminomethanol available in the literature at this time. All methods are in fair agreement. DMC appears to be an outlying point of the higher accuracy methods. This is likely a result of limited precision. DMC is a very expensive method, and the computational resources limited the attainable precision. The one standard deviation error estimates provided are still in rough agreement with QCI(T) and $\operatorname{CCSD}(\mathrm{T})$.

The verification of the formation mechanism provides little new insight. The results obtained from the traditional higher-level methods provide similar results to those obtained in previous work. ${ }^{9}$

The barrier to elimination of water is $55 \mathrm{kcal} / \mathrm{mol}$ at ambient temperatures, indicating that the conversion to methanimine is highly thermodynamically unfavored under typical laboratory and interstellar gas-phase conditions (Fig. 3 ). The barrier to formation of aminomethanol is also quite high $(41 \mathrm{kcal} / \mathrm{mol})$, which indicates that decomposition back to the reactants is also thermodynamically unfavored.

In addition to its thermodynamic stability, this result also means that the formation of aminomethanol by this route is hindered thermodynamically. Its laboratory production may therefore prove to be quite difficult and other options must be explored. It is likely that interstellar aminomethanol could form through grain surface reaction schemes involving a radical mechanism, as is proposed in Refs. 2-4, rather than the route examined in this study. The results found here indicate that while the addition of ammonia to formaldehyde is not a viable process for aminomethanol formation, once aminomethanol forms from some other mechanism it will indeed remain thermodynamically stable from decomposition.

Infinite-pressure Rice-Ramsperger-Kassel-Marcus (RRKM) theory can be used to predict the upper bound for

TABLE II. Absolute energies (hartree) for various methods (basis: aug-cc-pVTZ).

\begin{tabular}{|c|c|c|c|c|c|c|c|}
\hline Method & $\mathrm{NH}_{3}$ & $\mathrm{CH}_{2} \mathrm{O}$ & $T_{\mathrm{NH}_{3}+\mathrm{CH}_{2} \mathrm{O}}^{\dot{\dagger}}$ & $\mathrm{CH}_{2}(\mathrm{OH}) \mathrm{NH}_{3}$ & $T_{\mathrm{H}_{2} \mathrm{O}+\mathrm{CH}_{2} \mathrm{NH}}^{\dagger}$ & $\mathrm{H}_{2} \mathrm{O}$ & $\mathrm{CH}_{2} \mathrm{NH}$ \\
\hline B3LYP & -114.5520 & -56.5887 & -171.0922 & -171.1594 & -171.0698 & -76.4660 & -94.6719 \\
\hline $\mathrm{BLYP}^{\mathrm{a}}$ & -114.5259 & -56.5619 & -171.0390 & -171.1009 & -171.0214 & -76.4489 & -94.6355 \\
\hline $\mathrm{BP}^{\mathrm{a}}{ }^{\mathrm{a}}$ & -114.5497 & -56.5868 & -171.0983 & -171.1576 & -171.0779 & -76.4658 & -94.6680 \\
\hline $\mathrm{HF}^{\mathrm{a}}$ & -113.9140 & -56.2201 & -170.0633 & -170.1503 & -170.0313 & -76.0600 & -94.0696 \\
\hline $\mathrm{HF}^{\mathrm{b}}$ & -113.9142 & -56.2202 & NA & NA & NA & -76.0603 & -94.0697 \\
\hline$M P 2^{b}$ & -114.3460 & -56.4722 & NA & NA & NA & -76.3337 & NA \\
\hline $\mathrm{MP} 4^{\mathrm{b}}$ & -114.3254 & -56.4810 & NA & NA & NA & -76.3437 & NA \\
\hline $\mathrm{CCSD}^{\mathrm{b}}$ & -114.3254 & -56.4722 & NA & NA & NA & -76.3337 & NA \\
\hline $\operatorname{CCSD}(\mathrm{T})^{\mathrm{b}}$ & -114.3427 & -56.4806 & NA & NA & NA & -76.3423 & NA \\
\hline $\mathrm{QCI}(\mathrm{T})^{\mathrm{b}}$ & -114.3433 & -56.4807 & NA & NA & NA & -76.3426 & NA \\
\hline
\end{tabular}

JAGUAR.

${ }^{\mathrm{b}}$ MOLPRO. 
TABLE III. Relative free energies $\Delta G(\mathrm{kcal} / \mathrm{mol})$ for various methods with cc-pVTZ basis with JAGUAR B3LYP/cc-pVTZ(-f) zero-point and thermochemical corrections at $2.63 \times 10^{-5}$ atm and $300 \mathrm{~K}$.

\begin{tabular}{|c|c|c|c|c|c|}
\hline Method & $\begin{array}{c}\mathrm{NH}_{3} \text { and } \\
\mathrm{CH}_{2} \mathrm{O}\end{array}$ & $T_{\mathrm{NH}_{3}+\mathrm{CH}_{2} \mathrm{O}}^{\dagger}$ & $\mathrm{CH}_{2}(\mathrm{OH}) \mathrm{NH}_{2}$ & $T_{\mathrm{H}_{2} \mathrm{O}+\mathrm{CH}_{2} \mathrm{NH}}^{\dagger}$ & $\begin{array}{l}\mathrm{H}_{2} \mathrm{O} \text { and } \\
\mathrm{CH}_{2} \mathrm{NH} \\
\end{array}$ \\
\hline B3LYP ${ }^{a}$ & -8.47 & 39.25 & 0 & 51.74 & -5.33 \\
\hline BLYP $^{a}$ & -12.06 & 35.56 & 0 & 45.04 & -8.25 \\
\hline $\mathrm{BP} 86^{\mathrm{a}}$ & -7.29 & 33.96 & 0 & 45.01 & -4.21 \\
\hline $\mathrm{HF}^{\mathrm{a}}$ & -10.28 & 51.72 & 0 & 70.30 & -6.91 \\
\hline $\mathrm{HF}^{\mathrm{b}}$ & -10.28 & 51.67 & 0 & 70.28 & 6.01 \\
\hline $\mathrm{MP} 2^{\mathrm{b}}$ & -5.58 & 39.67 & 0 & 54.40 & -3.75 \\
\hline $\mathrm{MP} 4^{\mathrm{b}}$ & -7.39 & 39.76 & 0 & 53.55 & -4.88 \\
\hline $\mathrm{CCSD}^{\mathrm{b}}$ & -6.62 & 43.17 & 0 & 59.01 & -5.09 \\
\hline $\operatorname{CCSD}(\mathrm{T})^{\mathrm{b}}$ & -6.73 & 40.91 & 0 & 55.07 & -5.28 \\
\hline $\mathrm{QCI}(\mathrm{T})^{\mathrm{b}}$ & -6.84 & 40.72 & 0 & 54.69 & -5.24 \\
\hline $\mathrm{DMC}^{\mathrm{c}}$ & NA & NA & 0 & $64(5)$ & $5(5)$ \\
\hline
\end{tabular}

JAGUAR.

${ }^{\mathrm{b}}$ MOLPRO.

CQMCBEAVER.

the unimolecular decomposition rate for aminomethanol, which is given by the expression for the rate, $k_{\mathrm{uni}}^{\infty}$,

$$
k_{\mathrm{uni}}^{\infty}=\frac{k_{B} T}{h} \frac{q_{r}^{\ddagger} q_{v}^{\ddagger}}{q_{r} q_{v}} e^{-E_{a} / k_{B} T},
$$

where $k_{B}$ is the Boltzmann constant, $h$ is Planck's constant, $T$ is the temperature, $E_{a}$ is the activation energy, and $q_{r}, q_{v}, q_{r}^{\ddagger}$, and $q_{v}^{\ddagger}$ are the rotational and vibrational partition functions for aminomethanol and the transition state, respectively. The calculated rates for 300,500 , and $1000 \mathrm{~K}$ for both the forward and reverse reactions are shown in Table VII. We have not included tunneling of the hydroxyl proton in these calculations due to the expected strength of the hydrogen bond. At $300 \mathrm{~K}$, the lifetime of aminomethanol is between $10^{7}$ and $10^{16} \mathrm{yr}$, indicating that it should be kinetically stable against

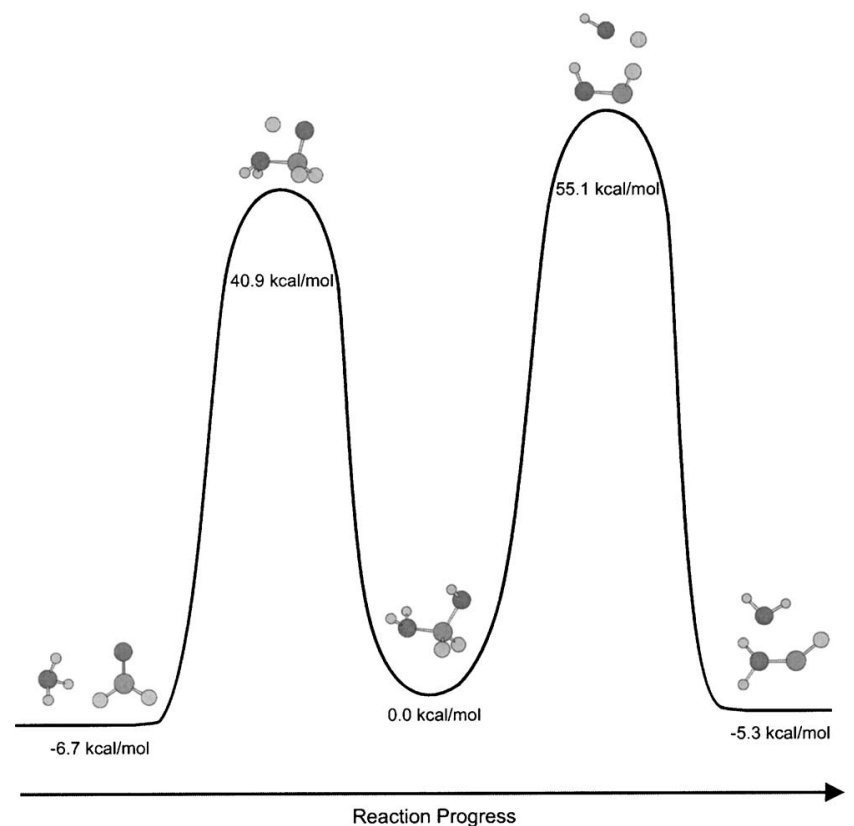

FIG. 3. Energy diagram of the formation and decomposition mechanism of aminomethanol.
TABLE IV. Relative free energies $\Delta G(\mathrm{kcal} / \mathrm{mol})$ for various methods with aug-cc-pVTZ basis with JAGUAR B3LYP/cc-pVTZ $(-f)$ zero-point and thermochemical corrections at $2.63 \times 10^{-5} \mathrm{~atm}$ and $300 \mathrm{~K}$.

\begin{tabular}{lrrcrr}
\hline \hline Method & $\begin{array}{c}\mathrm{NH}_{3} \text { and } \\
\mathrm{CH}_{2} \mathrm{O}\end{array}$ & $T_{\mathrm{NH}_{3}+\mathrm{CH}_{2} \mathrm{O}}^{\dagger}$ & $\mathrm{CH}_{2}(\mathrm{OH}) \mathrm{NH}_{2}$ & $T_{\mathrm{H}_{2} \mathrm{O}+\mathrm{CH}_{2} \mathrm{NH}}^{\dagger}$ & $\begin{array}{r}\mathrm{CH}_{2} \mathrm{O} \text { and } \\
\hline \text { B3LYP }^{\mathrm{a}}\end{array}$ \\
$\mathrm{BLYP}^{\mathrm{a}}$ & -8.99 & 38.70 & 0 & 51.34 & -7.08 \\
$\mathrm{BP}^{\mathrm{a}}$ & -12.49 & 35.36 & 0 & 44.96 & -10.30 \\
$\mathrm{HF}^{\mathrm{a}}$ & -7.47 & 33.75 & 0 & 45.09 & -5.65 \\
\hline \hline JAGUAR. & -10.57 & 51.05 & 0 & 69.76 & -7.66 \\
\hline
\end{tabular}

unimolecular decomposition under typical laboratory and hot core conditions.

A simple model was used to confirm that tunneling effects were minimal. In the following equation $V(x)$ is a simple Fourier expansion of the one-dimensional potential for the reaction coordinate, $a$ is the distance from the stable species to the transition state, $E^{\ddagger}$ is the barrier height, $f_{r x c}$ is the frequency of the mode along which the reaction occurs, and $m$ is the reduced mass of mode along which the reaction occurs.

$$
\begin{aligned}
& V(x)=E^{\ddagger}\left(\frac{1-\cos (\pi x / a)}{2}\right), \\
& x_{\min }=\arccos \left(1-\frac{2 E}{E^{\ddagger}}\right) \frac{a}{\pi}, \\
& x_{\max }=2 a-x_{\min }, \\
& r=f_{r x c} \int_{V\left(x_{\min }\right)}^{V\left(x_{\max }\right)} \exp \left(-E-\frac{2 \sqrt{k T}}{\hbar}\right. \\
& \left.\quad \times \int_{x_{\min }}^{x_{\max }} \sqrt{2 m(V(x)-E)} d x\right) d E .
\end{aligned}
$$

The stable species has linear combinations of its normal modes to reach the transition states, and the above expressions can be further simplified by considering only the major

TABLE V. Relative free energies $\Delta G(\mathrm{kcal} / \mathrm{mol})$ at $2.63 \times 10^{-5}$ atm for various temperatures with zero-point and thermochemical corrections from JAGUAR [B3LYP/cc-pVTZ(-f)] on energetics from MOLPRO [QCI(T)/cc-pVTZ].

\begin{tabular}{lrrrrr}
\hline \hline Temp & $\begin{array}{c}\mathrm{NH}_{3} \text { and } \\
\mathrm{CH}_{2} \mathrm{O}\end{array}$ & $T_{\mathrm{NH}_{3}+\mathrm{CH}_{2} \mathrm{O}}^{\dagger}$ & $\mathrm{CH}_{2}(\mathrm{OH}) \mathrm{NH}_{2}$ & $T_{\mathrm{H}_{2} \mathrm{O}+\mathrm{CH}_{2} \mathrm{NH}}^{\dagger}$ & $\begin{array}{c}\mathrm{H}_{2} \mathrm{O} \text { and } \\
\mathrm{CH}_{2} \mathrm{NH}\end{array}$ \\
\hline 0 & 8.84 & 40.58 & 0 & 54.74 & 10.14 \\
100 & 4.37 & 40.59 & 0 & 54.71 & 5.76 \\
200 & -1.12 & 40.62 & 0 & 54.69 & 0.38 \\
300 & -6.84 & 40.72 & 0 & 54.69 & -5.24 \\
400 & -12.63 & 40.87 & 0 & 54.69 & -10.94 \\
500 & -18.43 & 41.07 & 0 & 54.69 & -16.64 \\
600 & -24.21 & 41.30 & 0 & 54.69 & -22.33 \\
700 & -29.95 & 41.55 & 0 & 54.69 & -28.00 \\
800 & -35.66 & 41.82 & 0 & 54.69 & -33.63 \\
900 & -41.34 & 42.11 & 0 & 54.69 & -39.23 \\
1000 & -46.98 & 42.41 & 0 & 54.70 & -44.80 \\
1100 & -52.59 & 42.71 & 0 & 54.71 & -50.34 \\
\hline \hline
\end{tabular}


TABLE VI. Relative free energies $\Delta G(\mathrm{kcal} / \mathrm{mol})$ at $1.32 \times 10^{-8}$ atm for various temperatures with zero-point and thermochemical corrections from JAGUAR $[\mathrm{B} 3 \mathrm{LYP} / \mathrm{cc}-\mathrm{pVTZ}(-f)]$ on energetics from MOLPRO $[\mathrm{QCI}(\mathrm{T}) / \mathrm{cc}-$ pVTZ].

\begin{tabular}{lrrcrr}
\hline \hline Temp & $\begin{array}{c}\mathrm{NH}_{3} \text { and } \\
\mathrm{CH}_{2} \mathrm{O}\end{array}$ & $T_{\mathrm{NH}_{3}+\mathrm{CH}_{2} \mathrm{O}}^{\dagger}$ & $\mathrm{CH}_{2}(\mathrm{OH}) \mathrm{NH}_{2}$ & $T_{\mathrm{H}_{2} \mathrm{O}+\mathrm{CH}_{2} \mathrm{NH}^{\dagger}}$ & $\begin{array}{c}\mathrm{H}_{2} \mathrm{O} \text { and } \\
\mathrm{CH}_{2} \mathrm{NH}\end{array}$ \\
\hline 0 & 8.84 & 40.58 & 0 & 54.74 & 10.14 \\
100 & 2.86 & 40.59 & 0 & 54.71 & 4.25 \\
200 & -4.14 & 40.62 & 0 & 54.69 & -2.64 \\
300 & -11.37 & 40.72 & 0 & 54.69 & -9.77 \\
400 & -18.67 & 40.87 & 0 & 54.69 & -16.98 \\
500 & -25.98 & 41.07 & 0 & 54.69 & -24.19 \\
600 & -33.27 & 41.30 & 0 & 54.69 & -31.39 \\
700 & -40.53 & 41.55 & 0 & 54.69 & -38.57 \\
800 & -47.75 & 41.82 & 0 & 54.69 & -45.71 \\
900 & -54.93 & 42.11 & 0 & 54.69 & -52.82 \\
1000 & -62.08 & 42.41 & 0 & 54.70 & -59.91 \\
1100 & -69.20 & 42.71 & 0 & 54.71 & -66.96 \\
\hline \hline
\end{tabular}

normal mode in each case. This provides a lower estimate on $a$ and hence an upper bound for the tunneling rates.

For the $\mathrm{H}_{2} \mathrm{O}+\mathrm{CH}_{2} \mathrm{NH}$ and $\mathrm{NH}_{3}+\mathrm{CH}_{2} \mathrm{O}$ reaction pathways, $m$ is 7.1 and 1.7 amu, $a$ is 0.88 and $2.14 \AA$, and $f_{r x c}$ is 806 and $265 \mathrm{~cm}^{-1}$, respectively. This leads to reaction rates for $T=300 \mathrm{~K}$ of $2.8 \times 10^{-27} \mathrm{~s}^{-1}$ and $8.0 \times 10^{-18} \mathrm{~s}^{-1}$, for these reactions, respectively. Tunneling effects at $300 \mathrm{~K}$ are negligible for both the formation and decomposition pathways, so tunneling will not be a factor under laboratory or hot core conditions. Tunneling effects are not negligible at $1000 \mathrm{~K}$, however, but this temperature is far above the temperatures in the laboratory or astrophysical environments so tunneling will not be a factor in spectroscopic or observational studies.

Due to its thermodynamic and kinetic stability, loss of aminomethanol can be virtually eliminated by minimizing reactions with other species in a molecular-beam experiment. Spectroscopic characterization of aminomethanol should therefore be a straightforward process once a favorable formation route is determined.

In conclusion, these results indicate that aminomethanol could indeed be a stable species in hot core environments, which are typically near ambient temperatures. Aminomethanol is predicted to be present in abundances similar to those for observed alcohols in hot cores. However, the formation of this molecule under laboratory conditions will be quite difficult, and other formation schemes must be explored. Once the laboratory characterization is complete, however, aminomethanol will be an ideal target for observational searches.

TABLE VII. B3LYP/cc-pVTZ(-f). Decomposition of aminomethanol into $1 \mathrm{NH}_{3}$ plus $\mathrm{CH}_{2} \mathrm{O}$ and $2 \mathrm{H}_{2} \mathrm{O}$ plus methanimine.

\begin{tabular}{ccccc}
\hline \hline \multirow{2}{*}{ Reaction } & \multicolumn{4}{c}{$k_{\text {ini }}^{\infty}\left(\mathrm{s}^{-1}\right)$} \\
& $100 \mathrm{~K}$ & $300 \mathrm{~K}$ & $500 \mathrm{~K}$ & $1000 \mathrm{~K}$ \\
\hline 1 & $6.5 \times 10^{-74}$ & $1.6 \times 10^{-16}$ & $5.3 \times 10^{-05}$ & $2.4 \times 10^{+04}$ \\
2 & $1.4 \times 10^{-100}$ & $2.4 \times 10^{-25}$ & $3.5 \times 10^{-10}$ & $1.1 \times 10^{+02}$ \\
\hline \hline
\end{tabular}

\section{ACKNOWLEDGMENTS}

One of the authors (M.T.F.) thanks the Computational Science Graduate Fellowship Program of the Office of Scientific Computing and Office of Defense Programs in the Department of Energy under Contract No. DE-FG0297ER25308. Two of the authors (S.L.W.) and (G.A.B.) thank the NASA Exobiology and SARA programs, Grant Nos. NAG5-8822 and NAG5-11423. Another author (D.R.K.) thanks the Fannie and John Hertz Foundation for financial support. The computational resources at the MSC were provided by the NSF (CHE-99MRI), IBM (SUR Grant), and ARO-DURIP (1997). Lawrence Berkeley, Lawrence Livermore, and Los Alamos National Laboratories provided much of the computational resources for the development of high accuracy parallel quantum mechanical methods. LBL provided a test facility for large scale heterogeneous parallelization while LANL and LLNL were under the DOE ASCI ASAP project at Caltech. Other support for the MSC came from NIH, Chevron-Texaco, 3M, Avery-Dennison, Dow, GM, Seiko-Epson, Beckman Institute, Asahi Chemical, and Nippon Steel.

${ }^{1}$ M. Ohishi, in Molecules in Astrophysics, IAU Symposium No. 178, edited by E. van Dishoeck (Kluwer, Dordrecht, 1997), pp. 61-74.

${ }^{2}$ S. Charnley, Astrophys. J. 448, 232 (1995).

${ }^{3}$ S. Charnley, in The Bridge Between the Big Bang and Biology (Consiglio Nazionale delle Ricerche, Italy, 1999).

${ }^{4}$ S. Charnley, in Astronomical and Biochemical Origins and the Search for Life in the Universe, edited by C. B. Cosmovici, S. Bowyer, and D. Werthimer (Editrice Compositori, Bologna, 1997), p. 89.

${ }^{5}$ J. M. Hollis, F. J. Lovas, and P. R. Jewell, Astrophys. J. 540, L107 (2000)

${ }^{6}$ S. L. Widicus-Weaver and G. A. Blake, Astrophys. J. (to be published). ${ }^{7}$ R. E. Penn and R. F. Curl, J. Chem. Phys. 53, 651 (1971).

${ }^{8}$ S. L. Widicus, B. J. Drouin, K. A. Dyl, and G. A. Blake, J. Mol. Spectrosc. 217, 278 (2002).

${ }^{9}$ R. M. Minyaev and E. A. Lepin, Mendeleev Commun. 5, 189 (1997).

${ }^{10}$ A. T. Nielsen, D. W. Moore, M. D. Ogan, and R. L. Atkins, J. Org. Chem. 44, 1678 (1979).

${ }^{11}$ A. D. Becke, Phys. Rev. A 38, 3098 (1988).

${ }^{12}$ C. Lee, W. Yang, and R. G. Parr, Phys. Rev. B 37, 785 (1988).

${ }^{13}$ A. D. Becke, J. Chem. Phys. 98, 5648 (1993).

${ }^{14}$ J. P. Perdew, Phys. Rev. B 33, 8822 (1986).

${ }^{15}$ A. D. Becke, J. Chem. Phys. 84, 4524 (1986).

${ }^{16}$ M. N. Ringnalda, J.-M. Langlois, R. B. Murphy et al., JAGUAR v4.0, 2001.

${ }^{17}$ R. Lindh, Theor. Chim. Acta 85, 423 (1993).

${ }^{18}$ A. E. Azhary, G. Rauhut, P. Pulay, and H.-J. Werner, J. Chem. Phys. 108, 5185 (1998)

${ }^{19}$ F. Eckert, P. Pulay, and H.-J. Werner, J. Comput. Chem. 18, 1473 (1997).

${ }^{20}$ F. Eckert and H.-J. Werner, Theor. Chim. Acta 100, 21 (1998).

${ }^{21}$ C. Hampel and H.-J. Werner, J. Chem. Phys. 104, 6286 (1996).

${ }^{22}$ G. Hetzer, P. Pulay, and H.-J. Werner, Chem. Phys. Lett. 290, 143 (1998).

${ }^{23}$ M. Schutz, G. Hetzer, and H.-J. Werner, J. Chem. Phys. 111, 5691 (1999).

${ }^{24}$ C. Hampel, K. Peterson, and H.-J. Werner, Chem. Phys. Lett. 190, 1 (1992).

${ }^{25}$ R. D. Amos, A. Bernhardsson, A. Berning et al., MOLPRO, a package of $a b$ initio programs designed by H.-J. Werner and P. J. Knowles, version 2000.1, 2000

${ }^{26}$ C. Umrigar, M. Nightingale, and K. Runge, J. Chem. Phys. 99, 2865 (1993).

${ }^{27}$ M. T. Feldmann and D. R. Kent IV, QMCBEAVER v20020109, 2001.

${ }^{28}$ M. T. Feldmann, Ph.D. thesis, California Institute of Technology, 2002. 
${ }^{29}$ D. R. Kent IV, Ph.D. thesis, California Institute of Technology, 2003; http://resolver.caltech.edu

${ }^{30}$ D. R. Kent IV and M. T. Feldmann, QMCBEaVer, SourceForge: GNU Public License; quantum Monte Carlo open-source software; http:// sourceforge.net/projects/qmcbeaver
${ }^{31}$ T. Dunning, J. Chem. Phys. 90, 1007 (1989).

${ }^{32}$ See EPAPS Document No. E-JCPSA6-123-304527 for geometries of all species. This document can be reached via a direct link in the online article's HTML reference section or via the EPAPS homepage (http:// www.aip.org/pubservs/epaps.html). 